\title{
Training Amateur Bandsmen to Perform at Functions: COLTEK Band in Perspective
}

\author{
George Asabre Maclean" \\ Department of Music Education, University of Education, Winneba, Ghana
}

*Corresponding Author: George Asabre Maclean, Department of Music Education, University of Education, Winneba, Ghana

\begin{abstract}
The study was an action research to assist bandsmen of the College of Technology (COLTEK), University of Education, Winneba (UEW) in Ghana, within a short period of time, to perform at the University's Congregation ceremony. A preliminary diagnostic test conducted revealed among the challenges encountered by the bandsmen as inability to read musical staff notation, and then limited knowledge of keys and their scales. Observations, auditioning and personal interactions were employed as data collection instruments while solfege, varied rehearsal techniques and phrase by phrase approaches were used as the main interventions. Hinged on the theory of expectation, the paper concludes that with the appropriate rehearsal techniques, a band can be prepared within a short time to gain proficiency for public performances in spite of its infantile nature and the less knowledge in theory among the bandsmen. It is recommended that the interventions are employed by tutors and trainers of new bands to deal with fundamental instrumental playing techniques for public performances.
\end{abstract}

Keywords: COLTEK, Solfege, Rehearsal, UEW, Congregation, Matriculation

\section{INTRODUCTION}

College of Technology (COLTEK) is one of the satellite campuses of the University of Education, Winneba (UEW) in Ghana which hosts students pursuing Technical and Vocational as well as Business Education programmes on full time, part-time and distant basis. It is one of the institutions amalgamated into the University, among the National Academy of Music (NAM, in Winneba), School of Ghanaian Languages (in Ajumako), Kwame Nkrumah Ideological Institute (in Winneba), Winneba Sports College (in Winneba) and College of Agric (Mampong). The university has its main administration in Winneba, having the North, South and Central campuses in the same municipality. The College of Languages of Education at Ajumako in the Central Region of Ghana, the College of Technology Education (COLTEK) and the College of Agriculture Education in Kumasi and AsanteMampong respectively.

At every major function or ceremony by the university, the role of the winds ensemble in providing music at the ceremony is indispensable. Three anthems are rendered in the following order: the Ghana National Anthem, the University's anthem (also known as the Victory Anthem) and the National Song (Y\&n Ara Asaase Ni). These anthems are rendered with accompaniment by the band. With the band's availability in the Winds Unit of the university's Department of Music Education, the anthems are rendered to the admiration of all - students, staff of the university as well as special invited guests. It is even on record that the then president of the Republic of Ghana, His Excellency, John Dramani Mahama (President, 2012-2016) who attended the 2014 congregation ceremony in Winneba campus pronounced the rendition of the Ghana National Anthem by the Winds Band of the university as the best he had heard so far. Similarly, he considered the Victory Anthem of the University as the best among the university anthems in Ghana. This is probably due to the quality of the performance of the band as well as what music can do in such contexts. Music is experienced in many different contexts and plays an important role in many social contexts such as weddings, funerals, and parties. Blood and Zatorre (2001) observed the importance of music to human beings and stated:

music affects us in ways that are personal and require psychological explanation: music energizes, surprises, soothes, delights, and otherwise shapes our emotional states. Research in cognition and neuroscience supports the idea that pleasure and emotions are key motivations for listening to music. Not only does music activate "pleasure centers" in the brain. (p.34) 
Music can communicate and induce a range of powerful emotions (Juslin \& Laukka, 2003) and that is why the University finds it expedient to fall on its Band from the Music Education Department (in Winneba campus) to render those pieces during its statutory functions.

In the University, two major programmes reckoned on the university's annual academic calendar are the Matriculation ceremony, held for newly admitted students and then Congregation ceremony for graduating students. Since the establishment of the university, the three anthems have been mandatory to be accompanied by the band at these two statutory functions. It is not very clear why the concentration is on the three anthems but it seems possible that as a state institution, such functions pave the way to imbibe patriotism into the people through music. Similarly, music is performed in terms of how it expresses local issues and concerns, often quite removed from the circumstances that inspired the music's creation, dramatically changing the meaning across locations and especially cultures ((McEnnis \& Cunningham, 2007, p.1). These anthems are performed so well at these functions in Winneba ceremonies. Unfortunately, the quality of musical performance experienced in Winneba is not felt in Kumasi, where eventually the climax of the programmes at all campuses is held.

Indeed, considering the distance between the seat of the university, Winneba, and that of its campus in Kumasi, and the inevitability of music at such ceremonies, as observed by Manoff (1982), a critical question arises as to how the three anthems could be rendered at such ceremonies. Among the options the university could consider were (1) to send the band from Winneba to the Kumasi Campus to perform and (2) to have the anthems recorded and played for graduands or matriculants in Kumasi to sing along. The implication for each of the options mentioned could not be cogitated about as convenient because each presented its own challenges. For instance, the option of sending the contingent of bandsmen from Winneba to Mampong and Kumasi could be very expensive, considering transporting them to and fro, the challenges with accommodation, and feeding them whilst the recording and making students sing along the playback could also result in a dissimilitude in performance, in terms of tempo and rhythm. In this regard, there was the need to get a similar band at COLTEK to provide music or render the anthems during such ceremonies. Acquiring such a band also required a competent instructor to prepare the band to perform well at such functions.

For this reason, the then Principal of the College of Technology, Kumasi, Professor E. J. Flolu, bought a set of brass instruments and percussion for students to learn and play to accompany the singing of the anthems during major functions by the university in Kumasi in 2012. As untrained as the Bandsmen were, it became significant for them to be trained towards the ceremonies. Within the period, the band managed to perform at some of the functions in Kumasi but their performances did not meet the expectations of both the participants of the ceremony as well as the management of the University. It is based on this background that I was contracted by the University to prepare these amateur bandsmen for one of the congregations in COLTEK. This decision therefore brought me, as a lecturer in charge of the Winds Band in Winneba, close to the COLTEK band to undertake the study.

\subsection{Perceived Problem}

The problem was perceived when the regular members of the planning committee for the university's congregation, other officers and staff of the university who had had the privilege of witnessing the annual matriculation and congregation ceremonies, both in Winneba and Kumasi took cognisance of a very strong dichotomy between the rendition of the anthems done in Winneba and that of its Kumasi campus. It was therefore perceived that the vitality of musical performance in Winneba stood in stark contrast to that of Kumasi Campus and therefore, the latter needed attention.

\subsection{Problem Diagnosis}

Having been tasked by the 18th Congregation planning committee's decision, to prepare the band for the November 2013 congregation at Kumasi, I visited the Band to acquaint myself with the problem identified. I went to Kumasi, from Winneba, to meet the band for the first time. After a short exchange of pleasantries and establishment of rapport with the bandsmen, a diagnostic test was done by way of auditioning where the band was asked to play the three anthems as they knew them and had also been playing them. The following diagnosis were done:

- Auditioning of the playing of the three anthems

- observation of the horns men's fingering on the valve 
- observation of the sliding on the slide instruments

\subsection{Problem Statement}

The major challenge met was the bandsmen's inability to play their music in other keys apart from the key of E flat major. Unfortunately, none of the three anthems was found in the key the band was familiar with. They found it difficult playing the scales of the correct keys of the three anthems. This is because they were familiar with only one key. It was also realized that the few chromatic notes in the songs were difficult to be played by them. As a result, they lacked good intonation as well as accurate interpretation of notes and rhythms of the pieces. It was evident that most of the bandsmen had not been on the instruments for long and therefore had problems with producing high pitches in some of their passages. Correct fingering positions, embouchure techniques, sliding of instruments for pitch accuracy and blowing techniques were found to be improved to ensure that expectations of the management and the planning committee were met.

\subsection{Objectives}

The research intended to:

- assist the bandsmen achieve good intonation

- support them play scales of the keys of the three anthems

- help the bandsmen play in the correct keys of the anthems

\subsection{Interventions}

In dealing with the problems, the following interventions were put in place:

- phrase by phrase approach

- use of solfege

- varied rehearsal techniques

\subsection{Research Questions}

The following research questions guided the study:

- in what ways can the use of phrase by phrase approach assist bandsmen achieve good intonation?

- how can varied rehearsal techniques help bandsmen to play in correct keys?

- to what extent can the use of solfege improve playing among amateur Bandsmen?

\section{THEORETICAL FrameWORK AND REVIEW OF RELATED LiTERATURE}

Huron (2006) developed what he called the ITPRA theory of musical expectancy, extended ideas of Meyer (1956) and Mandler (1984). He identified several ways in which expectations with music by an audience can cause nuanced emotions. According to him, these expectations may include imagination, tension, prediction, reaction and appraisal. Thompson and Quinto (2011) spoke about the ITPRA theory and explained what each of the letters stands for:

Imagination entails contemplating future states and acting in a way that makes those states more likely if they are positive and less likely if they are negative. Tension is an immediate physiological preparation for an imminent event and involves changes in arousal. Prediction is a transient state of reward or punishment that arises in response to the accuracy of expectation. Reaction and appraisal are emotional states that arise from assessments of the event itself independent of whether that event was anticipated. (p.367)

Indeed, the expectations of audience of the congregation and matriculation ceremonies are directly linked with this theory. It is therefore important in this regard to ensure musical synchronization in any public musical performance. This synchronization appears at the level of effective preparation of the musical ensemble that features at the heart of such occasions. It is worth stating that, one very important aspect of the rendition or performance of a nation's or an institution's anthem is the instrumental accompaniment that goes with the singing of the song by the participants. The accompaniment can be through different mediums including percussion, the keyboard, a symphony orchestra, a brass or military band. The quality of an anthem rendition can be greatly enhanced or 
marred by the accompaniment. In the event where a newly formed student brass band such as the College of Technology, Kumasi (COLTEK) in the University of Education, Winneba band is faced with the task of accompanying anthems at major ceremonies of the institution, it is prudent that much attention is paid to rehearsals of the pieces.

Many scholars have studied various techniques of instrumental teaching in context of their cultural setting as well as mental status of the instrumentalists (Colwell, Hewitt \& Fonder, 2017; Costa \& Lowery, 2016; Zhukov, 2012; Azzara, 1993; Wallace, Liberman, MacKain, Blackwell \& Eckman, 1992; Kohut, 1973). All these researches concentrated on wide range of orchestral and keyboard teaching over a period of time; however, an action research to improve particular competency within a limited time for public performances has not received much attention. Nevertheless, an instrumental specialist, Thornton \& Ocasio (2008), developed some effective rehearsal techniques based on the following strands to be adopted for band rehearsals.

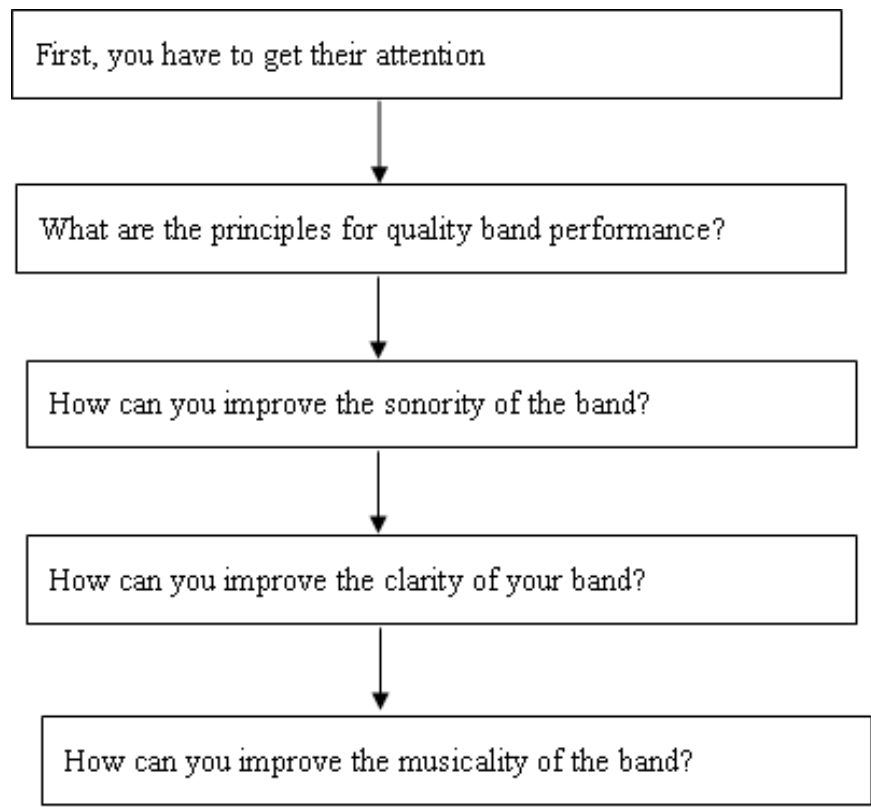

Suggested rehearsal framework by Paula Thornton

In this framework, they suggested that the physical environment conducive to learning should be neat, clean and uncluttered. The environment needs to be well organized and functional, free of outside noise and distraction, whether aural or visual. According to them, the band master needs to communicate and implement a procedural system for rehearsals. This may include how to enter the room, where to find the list of music to be rehearsed that day, where to check for other important announcements and information and how to get instruments from storage area. Similarly, how and where to store empty cases, process for making or adjusting set (chairs and stands), procedure in the case of tardiness or absence (immediate and follow-up) as well as warm-up and tuning proceduresroutine combined with some variation to provide a blend of consistent reinforcement and interest. Other things to consider may be the required items for rehearsal instruments such as the musical scripts, pencils and accessories, rehearsal policies and procedures (rules) and then end of class (or rehearsal) procedure.

Again, they stressed on sonority, clarity and musicality as good principles in quality band performance. For them, sonority is characterized by tone production which includes balancing, blending and intonation. While they stress on time, accuracy of notes and rhythms, vertical alignment and articulation as ensuring the clarity of band performance, they are of the view that musicality encompasses interpretation, style projection and expression. Unarguably, these principles are very good to ensure good quality performance that would certainly satisfy the expectations of the audience. Some of these principles were found significant to train the COLTEK Band to achieve good intonation and an equality of sound because, "a good brass ensemble must have an equality of sound from top to the bottom" (Whitener, 2007, p. 344).

A very crucial aspect of every organisation or group coming together for a common purpose is the issue of leadership. Getting a transformational leader who is well versed with the focus of the 
organization is crucial to its developmental goals. Like Hoch, Bommer, Dulebohn and Wu (2018) observed, transformational leadership, by itself, is a robust predictor. A transformational leader is therefore very important to ensure a robust skill development, especially, for a new established winds ensemble because the kind of leadership or direction given has a great impact on the performance by the group. Thus, the COLTEK band was met without a leader or a director who had much knowledge about Music as a subject and who could have much interest to direct winds ensemble. The leader needs a strong personal interest in maintaining his organization (Hofstede, 1983) because without the personal interest, the growth of the organization is at stake. This personal interest is generated by one's strong knowledge in the basic activities of the group. Generally, the minimal expectation is that the leader will not allow his group to decline or collapse since the reputation of the leader depends upon successful fulfillment of this minimal function. I, therefore, believe strongly that the absence of a leader for the band contributed to their inability to perform well at the various ceremonies. Getting the right scores and arrangements of the anthems had been a factor and therefore the bandsmen relied heavily on how they had heard the anthems performed traditionally.

The use of solfege in teaching instrumental skills has been found important, especially in music education. Feierabend (2001) did a research in music learning and the research resulted in two music curricula: 1. First steps in music and 2. Conversational solfege. The former describes a music and movement programme for infants through early elementary aged children whilst the latter is a music literacy method for use in general music classroom. The solmization (movable tonic pitch system) espoused by Kodaly aligns with the solfege instructional mechanism. McClung (2008) was of the view that with the solmization by Kodaly, students are taught to associate a specific scale degree with a specific solmization syllable though his view was the combination of the solmization with the specific shape and thoracic location of a hand sign, however, Reifinger (2012) confirmed that solfège with familiar patterns and a neutral syllable (loo) with unfamiliar patterns will result in significantly greater contour accuracy. The use of the solfege in training the band was inevitable as a result of the musical illiteracy of most of the bandsmen. Besides, the interventions adopted for the training were based on the duration of preparation as well as the level of education of the bandsmen. Dunn and Dunn (1993) commented on choice of learning styles that they are usually based on each person's environmental, emotional, sociological, physiological, and cognitive processing preferences. $\mathrm{He}$ further explained that cognitive processing modalities include auditory (listening), visual (reading), tactile (physical manipulation of materials), and kinesthetic. Based on these environmental characteristics of the trainees, the three interventions were used independently and complementarily to achieve the desired results.

\section{Methodology}

\subsection{Conduct of the Study}

The aim of the project was to assist the COLTEK Band, an amateur Brass ensemble to gain mastery on the rendition of the three anthems, within one week, at the $18^{\text {th }}$ Congregation Ceremony of the University. It was rooted in the action research. Like Somekh (1995) stated, "Action research is grounded in the culture and values of the social group whose members are both participants in the research field" (p.341). With this, the study targeted only the members of the Band who were 34 in number. These students who were members of the College's Brass Band were purposively sampled for the study. This number included a technician placed in charge of their tutelage.

In gathering data for the implementation of the interventions, observation, auditioning, and personal interactions were used. These instruments were specifically used at the diagnosis stage to detail their strengths and capabilities, both in knowledge and proficiency levels. During the first day, a meeting was held with the band. The main aim was to observe their level of dexterity on the instruments they handled in order to determine the starting point. The observation was also to find out the keys in which the three anthems were being played. In addition to that, auditioning was used to know exactly how the three anthems discussed earlier were performed. Personal interactions with the members of the band also took place the same day to find out their background in terms of their knowledge in music literacy and the playing of the instruments they were found on.

\subsection{Implementation of Interventions}

After the first day with the Band to identify their problems, the implementation of the interventions started the second day. As already stated, the interventions were used independently and 
complementarily depending on the situation at the time of the implementation. The first thing the researcher did was to guide the horns men to produce their pitches with good intonation. Notes on brass instruments require very subtle adjustments of embouchure, vowel formation, and air pressure to bring into tune as Whitener (2007) observed. Phrase by Phrase approach combined with other varied techniques were used to assist the bandsmen achieve that good intonation in their playing.

Having realised that the band could not read music from the musical staff but in tonic sol-fa, the researcher had to spend time after the first meeting to transcribe the scores of the anthems from staff notation to sol-fa for the players. The transcriptions had to be done for the various instruments available and used by the band. This was especially in the case of the University anthem (Victory anthem) which had different arrangements for the various instruments used in the composition as opposed to the Ghana National Anthem and the National Song which had been done in simple fourpart arrangements.

The phrase by phrase approach was followed by the use of the sol-fa notation to let them gain the scales of the keys of the anthems: A flat major, B flat major, and F major. Realising that the band was very familiar only with the key and scale of E flat major and also played using solfege, the scales were also given to them based on what they knew. Teaching them these scales involved giving the valve instrument players the fingering for the elements of the scales mentioned and the slide positions for those on the slide trombone. The valve instruments met with the band were B flat trumpets, B flat cornets, a valved trombone, euphonium, and B flat tuba, while the slide instruments were the tenor trombones used. Whereas the valve instruments usually have three valves to manipulate when playing, the slide trombone operates on slide positions which begin from when the slide is in its lock position or before any sliding is done.

The following tables, therefore, show the fingering and slide positions needed for the three keys in which the anthems are played.

N.B: The zero (0) in the fingering chart for the valve instruments means that the player does not need to press any of the valves for that pitch whilst the $1 / 2(2)$ ( $\mathrm{read}$ as "half two") in the slide position chart is an optional position for G3 on the trombone. It is a position between the first and second.

Fingering and Slide Position Chart for A flat Major Scale

\begin{tabular}{|c|c|c|c|c|c|c|c|c|c|c|c|c|c|c|c|}
\hline Letter Name: & $\mathrm{A}_{1}^{\mathrm{b}}$ & $\mathrm{B}_{1}^{\mathrm{b}}$ & $\mathrm{C}_{1}$ & $\mathrm{D}_{1}^{\mathrm{b}}$ & $\mathrm{E}_{1}^{\mathrm{b}}$ & $\mathrm{F}_{1}$ & $\mathrm{G}_{1}$ & $\mathrm{~A}^{\mathrm{b}}$ & $\mathrm{B}^{\mathrm{b}}$ & $\mathrm{C}$ & $\mathrm{D}^{\mathrm{b}}$ & $\mathrm{E}^{\mathrm{b}}$ & $\mathrm{F}$ & $\mathrm{G}$ & $\mathrm{A}^{\mathrm{b} 1}$ \\
\hline Solfege: & $\mathrm{d}_{1}$ & $\mathrm{r}_{1}$ & $\mathrm{~m}_{1}$ & $\mathrm{f}_{1}$ & $\mathrm{~s}_{1}$ & $\mathrm{l}_{1}$ & $\mathrm{t}_{1}$ & $\mathrm{~d}$ & $\mathrm{r}$ & $\mathrm{m}$ & $\mathrm{f}$ & $\mathrm{s}$ & 1 & $\mathrm{t}$ & $\mathrm{d}^{1}$ \\
\hline Fingering: & 1 & 0 & 1,3 & 2,3 & 1 & 0 & 1,2 & 1 & 0 & 1 & 2 & 1 & 0 & 1,2 & 1 \\
\hline Slide Positions: & 3 & 1 & 6 & 5 & 3 & 1 & 4 & 3 & 1 & 3 & 2 & 3 & 1 & $\mathrm{1} / 2(2)$ & 3 \\
\hline
\end{tabular}

Fingering and Slide Position Chart for B flat Major Scale

\begin{tabular}{|c|c|c|c|c|c|c|c|c|c|c|c|c|c|c|c|}
\hline Letter Name: & $\mathrm{B}_{1}^{\mathrm{b}}$ & $\mathrm{C}_{1}$ & $\mathrm{D}_{1}$ & $\mathrm{E}_{1}^{\mathrm{b}}$ & $\mathrm{F}_{1}$ & $\mathrm{G}_{1}$ & $\mathrm{~A}_{1}$ & $\mathrm{~B}^{\mathrm{b}}$ & $\mathrm{C}$ & $\mathrm{D}$ & $\mathrm{E}^{\mathrm{b}}$ & $\mathrm{F}$ & $\mathrm{G}$ & $\mathrm{A}$ & $\mathrm{B}^{\mathrm{b} 1}$ \\
\hline Solfege: & $\mathrm{d}_{1}$ & $\mathrm{r}_{1}$ & $\mathrm{~m}_{1}$ & $\mathrm{f}_{1}$ & $\mathrm{~s}_{1}$ & $\mathrm{l}_{1}$ & $\mathrm{t}_{1}$ & $\mathrm{~d}$ & $\mathrm{r}$ & $\mathrm{m}$ & $\mathrm{f}$ & $\mathrm{s}$ & 1 & $\mathrm{t}$ & $\mathrm{d}^{1}$ \\
\hline Fingering: & 0 & 1,3 & 1,2 & 1 & 0 & 1,2 & 2 & 0 & 1 & 0 & 1 & 0 & 1,2 & 2 & 0 \\
\hline Slide Positions: & 1 & 6 & 4 & 3 & 1 & 4 & 2 & 1 & 3 & 1 & 3 & 1 & $1 / 2(2)$ & 2 & 1 \\
\hline
\end{tabular}

Fingering and Slide Position Chart for F Major Scale

\begin{tabular}{|c|c|c|c|c|c|c|c|c|c|c|c|c|c|c|c|}
\hline Letter Name: & $\mathrm{F}_{1}$ & $\mathrm{G}_{1}$ & $\mathrm{~A}_{1}$ & $\mathrm{~B}^{\mathrm{b}}{ }_{1}$ & $\mathrm{C}_{1}$ & $\mathrm{D}_{1}$ & $\mathrm{E}_{1}$ & $\mathrm{~F}$ & $\mathrm{G}$ & $\mathrm{A}$ & $\mathrm{B}^{\mathrm{b}}$ & $\mathrm{C}$ & $\mathrm{D}$ & $\mathrm{E}$ & $\mathrm{F}^{1}$ \\
\hline Solfege: & $\mathrm{d}_{1}$ & $\mathrm{r}_{1}$ & $\mathrm{~m}_{1}$ & $\mathrm{f}_{1}$ & $\mathrm{~s}_{1}$ & $\mathrm{l}_{1}$ & $\mathrm{t}_{1}$ & $\mathrm{~d}$ & $\mathrm{r}$ & $\mathrm{m}$ & $\mathrm{f}$ & $\mathrm{s}$ & 1 & $\mathrm{t}$ & $\mathrm{d}^{1}$ \\
\hline Fingering: & 1,3 & 1,2 & 2 & 0 & 1,3 & 1,2 & 2 & 0 & 1,2 & 2 & 0 & 1 & 0 & 2 & 0 \\
\hline Slide Positions: & 6 & 4 & 2 & 1 & 6 & 4 & 2 & 1 & 4 & 2 & 0 & 3 & 1 & 2 & 1 \\
\hline
\end{tabular}

It is worth noting that the fingering chart provided was done in concert pitch. Concert pitch is the pitch reference to which a group of musical instruments are tuned for a performance and which may vary from ensemble to ensemble (Haynes, 2002). This means that the keys and the fingering given were done to make them sound in the keys mentioned. Contrary to the case of transposed fingering where the key mentioned and the fingering given make the key sound a tone lower in pitch, the players encountered were provided with the fingering that correspond directly to the keys mentioned. This was done as a result of the limited time available before the ceremony and also for uniformity in instruction because that was what the band was used to. Following the provision of the fingering and slide positioning were drills in the playing of the scales of the keys. These drills were to help the players acquaint themselves with the keys which, prior to, they were not familiar with. The players 
were then entreated to do their best to gain a mastery over the scales in order to have smooth rehearsal session the next day.

Varied rehearsal techniques were used subsequently during the implementation process. The second day of meeting the band offered an opportunity for the researcher and the bandsmen to confirm the transcriptions done for the anthems by way of playing or practicing them as transcribed. The first anthem tackled, among the three, was the Victory anthem. This anthem is of the quasi-polyphonic texture and therefore required more time to accomplish its study. Ample time was given to the introductory fanfare passage and the various rehearsal sections as indicated by rehearsal letters by the composer in the score. The introduction is illustrated in piano reduction score below:

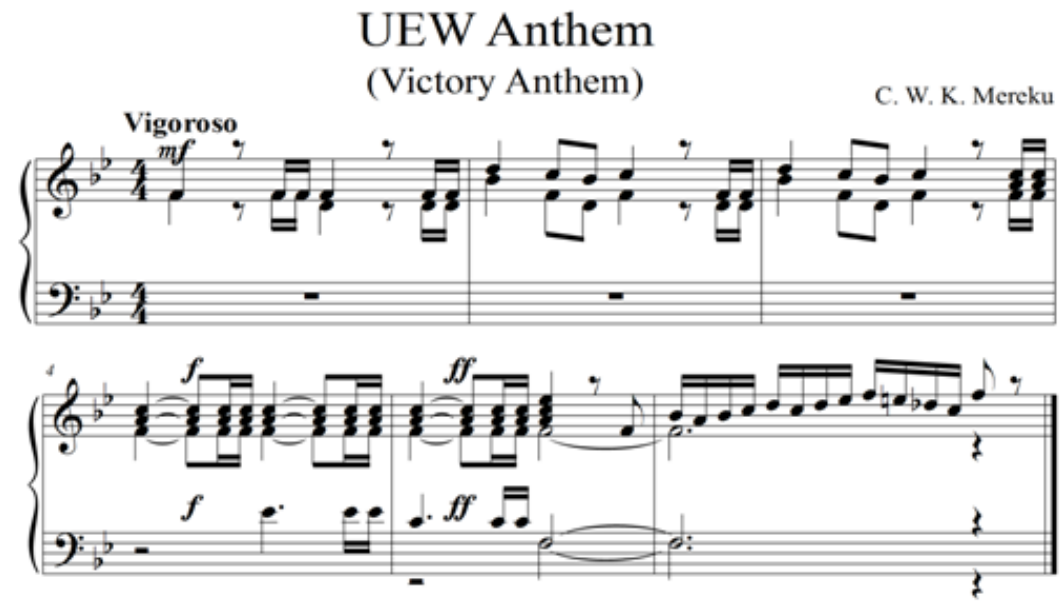

Figure1. Introductory passage to UEW Anthem

Each section was seen to it that it was well done before the next. Section by section, the full score could be rehearsed and played as expected of the instruments available for the first time by the band. The most challenging passage in the anthem, a runny passage by the Solo Trumpet just before the entry of the vocal part of the anthem, was left to two of the trumpeters to rehearse very well on their own after they were assisted with the rhythm and the fingering for some of the chromatic notes in the passage.

Following the University Anthem was the Ghana National Anthem in the key of A flat major.

\section{Ghana National Anthem}

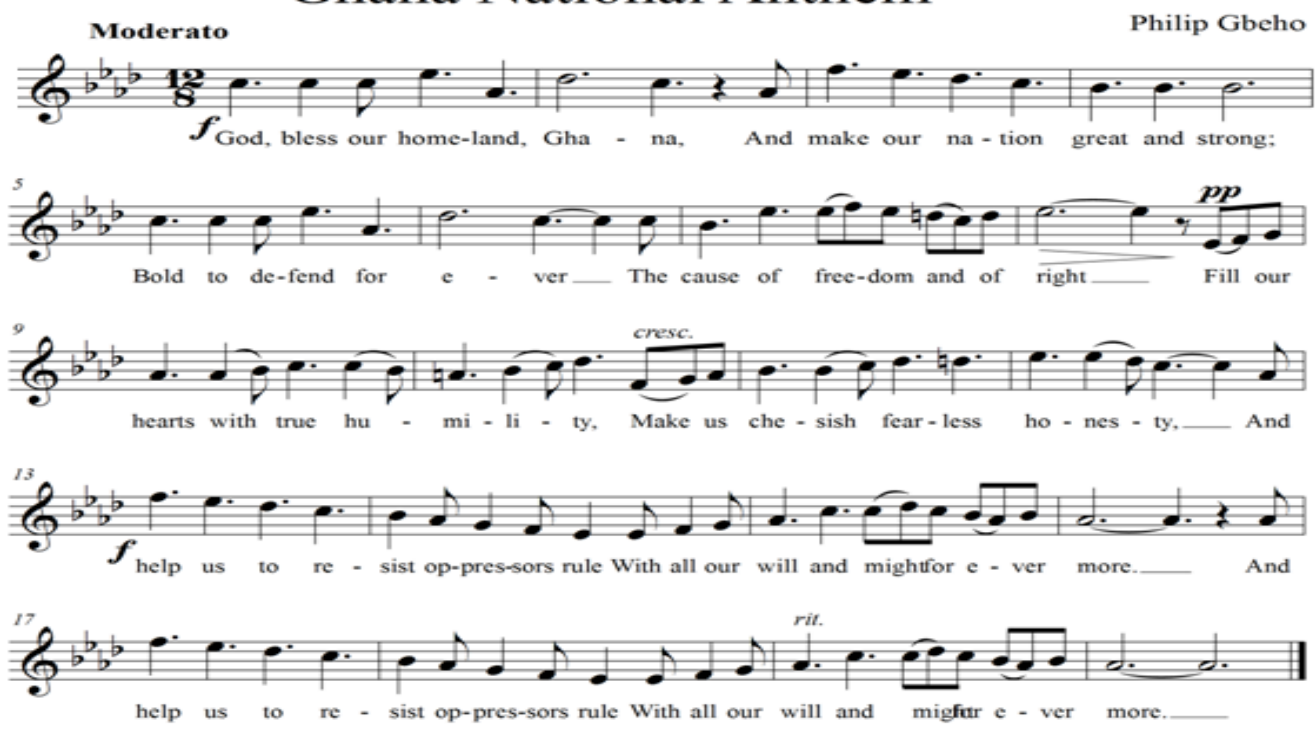

Figure2. Melody of Ghana National Anthem

After a revision of the running of the key's scale, the anthem, which was mainly with a homophonic texture, was begun. Cognisant of the fact the horns men were not very familiar with the key in question, attention was paid to the fingering and slide positioning of the notes involved in the anthem. Aside the fingering and slide positioning, the right or correct pitches were also given heed. The 
strategy adopted in this anthem was the phrase by phrase approach. Each phrase in the anthem was given special attention and after each phrase done, it was linked to the previous phrases tackled and played together - a practice the writer refers to as "conjunction". This practice is deemed necessary because it avoids the proclivity to forget previous passages or phrases done in the study of a piece and also helps the players to link phrases and sections as they practice the piece in full. Similarly, runny passages in the Trombone, Euphonium and Tuba parts were left with the players to take time and practice very well in the days the researcher was going to be away. This was after the players of the said instruments had been given an insight into the rhythm, fingering, and pitches for the runny passages. In all these, the chromatic notes within the anthems had to be taught in the course of learning to play them.

The last, but not least, of the three anthems, the National Song (Yen Ara Asaase Ni), whose arrangement is in simple four-part, homophonic in texture, and whose key appeared quite easier to play (among the three keys) - F major - was then rehearsed. The melody and lyrics of the song are illustrated in Figure 3.

\section{Yen Ara Asaase Ni}
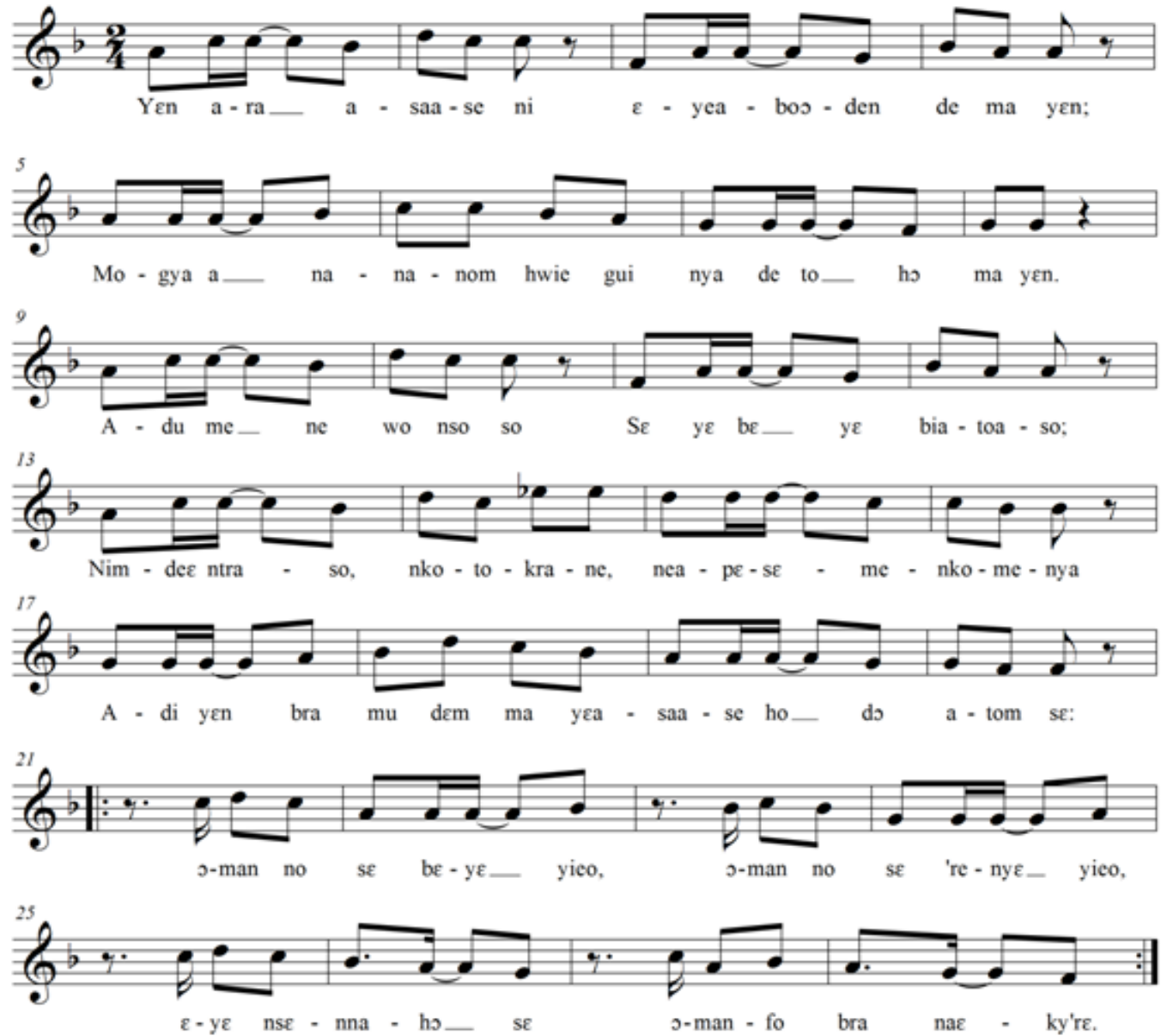

Figure3. Melody and lyrics of Yen Ara Asaase Ni (This is our own land), the Ghana National Song

This anthem, Yen Ara Asaase Ni, is one anthem in Ghana which is given different interpretation in terms of rhythm and pitches for the melody by different performers. The misinterpretation does not only pertain to winds band performers but also to soloists and choral groups and the general public. Consequently, the researcher had to pay strict attention and spend time to correct the wrong rhythms and pitches, especially, in the melody. The anthem was begun with a revision of the scale of the key in which the anthem was composed and is played. The scale was rehearsed in both ascending and descending order and in durations of four, two, and one count for each pitch in the scale. The drill was to get the players more acquainted with the fingering and slide positioning for the pitches that make the scale of the key. The bandsmen were first allowed to read and play the anthem on their own as the 
researcher observed the fingering and slide positioning used and the related pitches. Noting the weak and challenging passages in the anthem to the band, more attention was given to the phrases in the anthem, seeing to it that every set of instruments for each of the four parts had its part very well rehearsed. Here again, phrase by phrase, the anthem could be rehearsed in full.

The subsequent days witnessed an improvement in the pitching, accuracy and dexterity in fingering and slide positioning, as well as a fluency in the rhythmic patterns in the three anthems. The percussion section of the band had, by then, heard how the three anthems were supposed to be played and attention had to be paid to the section too. For each of the anthems, an accompaniment had to be given by the percussion. Due to the students' inability to interpret music on the musical staff, and for the percussion, rhythms on monotone, it took a practical demonstration of how the accompaniment for each of the anthems had to be played. Gradually, the full complement of each anthem was obtained.

These improvements were sustained and heightened approaching the days for the congregation ceremonies. Similar passages and excerpts from the three pieces were used as post-test. Post-test activities included individual, pairs and group performances. These post-tests were carried out to ascertain their level of dexterity in phrasal playing, scale renditions, good intonation, embouchure techniques and breath control.

\section{RESULTS AND DISCUSSION}

An enquiry from the bandsmen as to whether they could read music from the music staff yielded a negative response. Of the thirty-four (34) bandsmen met, only two (2) had knowledge of how to read from the staff. This, obviously, meant that the researcher had to devise a means by which the band could perform the anthems at an appreciable standard within the few weeks to the congregation ceremony. Congregation or Graduation ceremonies have been part of the history of Universities (Tuffour, 2012) and so such ceremonies will definitely need good musical performance to make it interesting and emotionally enjoyable.

The auditioning revealed that the band was familiar with only the key or scale of $E$ flat major, in which, virtually, every song of theirs was played. The audition scenarios challenge students' listening acuity for performance and performer evaluation, and confirm the importance of visual cues in music performance (Mitchell, 2018). Students became cognisant of the importance of sound and sight in their own performance preparation. It is interesting to note that the scale of $\mathrm{E}$ flat major appears to be one of the easiest scales for players of brass instruments; thus, the band choosing to play the anthems in that key. Nevertheless, the Ghana National Anthem was supposed to be played in the key of A flat major, the University Anthem in the key of B flat major, and the National Song in the key of F major. The implications, in this regard, were that the band sounded a fourth lower, in pitch, than expected for the Ghana National Anthem, sounded a fifth lower, in pitch, for the UEW Anthem and a second lower, in pitch, for the National Song. These further implied that the brightness, in terms of pitch, expected of the three aforementioned anthems was also lost. This low pitch in which the anthems were played, probably, provided the first mark of distinction between the main campus band and that of the Kumasi campus. Apart from the key used in playing the anthems, it was also noticed that the band played the anthems as they had heard them played or known but not as composed. This was mainly because it did not have the scores to the anthems or did not have them as arranged for band performance.

Other challenges encountered included a few members who had not been on the instruments for long and therefore had problems with producing high pitches in some of their passages. The notion that such pitches were too difficult to produce put them off and made them approach such pitches with difficulty, thereby failing to produce them as expected. As Papageorgi, Hallam \& Welch (2007) stated, "The degree of susceptibility to experiencing anxiety plays an important role in performance, as it can influence the performer's perceptions of the situation and their preparation procedures (p.84). They then had to be prepared psychologically to demystify high pitches and physically by using the right technique to produce such pitches. All the interventions put in place were workable and very effective to answer the research questions.

With the three anthems rehearsed in the right keys and as traditionally known to be performed by the Winds Band of the Department of Music Education for the first time by the COLTEK Band, the band was left with copies of the transcribed pieces in order to help them archive them for subsequent performances. After the implementation of the interventions, the enthusiasm with which the bandsmen gathered for the beginning of the final preparations for the ceremonies was very enormous. 


\section{INSIGHT GAINED}

For the first time since its inception, the College of Technology, Kumasi Band was able to perform the three anthems played during major programmes by the University of Education, Winneba, in the right keys, with the right arrangements and as composed, and also at the appropriate tempo. This was due to the right training and rehearsal techniques put in place to improve their play. Encountering a young band such as the COLTEK Band and being a college band which had students terminating their programmes of study and exiting annually presented a number of challenges. The termination and exit meant that the band would also have some members leaving whilst newly admitted students who may have the interest to join the band would also be making up for the vacuity left. This, therefore, meant that the band had a different set of members every academic year. It is therefore important that a seasoned academic musician who is into Winds band training is employed as a part-time tutor to have regular instructions with the band.

Furtherance to their inability to read the music from the musical staff, one would have thought that with the bandsmen being more familiar with the solfege, they could, as well, interpret the indications for long and short pitches written. However, the opposite was found to be true upon further interaction with the bandsmen. In spite of all the indications provided with the sol-fa notation, the bandsmen still found it challenging to give the pitches the right durations as indicated. This was especially in the case of the Ghana National Anthem which comes in a compound quadruple time. The researcher then had to sing virtually every passage to them in order to get the right thing played. Regular training and leadership would be appropriate to deal with such circumstances.

Again, the instrumentation available to a band contributes immensely to the taste of its renditions. In this sense, classes of instruments found in the COLTEK Band was without Woodwinds, thereby making it more of a brass band than the military band experienced in the main campus.

\section{CONCLUSION}

From the foregoing discussions, it is worth stating that providing a college with a band and giving it quality or professional leadership and training goes a long way to enhance its performance. Similarly, inability of a band to interpret music from the musical staff should not be a hindrance to its ability to perform pieces as composed or arranged. Furthermore, no matter how short the time may be for the preparation of a band for a performance, the piece(s) to be performed can be tackled phrase by phrase. This practice may appear boring to some bandsmen but from the experience gathered so far by the researcher, it is very effective and the repetitions done for the phrases eventually brings about accuracy. With the varied rehearsal techniques to train a band, the expectations of graduands, matriculants, staff and all guests of such statutory ceremonies of the University, be it Winneba or Kumasi, will be fully met.

\section{REFERENCES}

[1] Azzara, C. D. (1993). Audiation-based improvisation techniques and elementary instrumental students' music achievement. Journal of Research in Music Education, 41(4), 328-342.

[2] Blood, A. J., \& Zatorre, R. J. (2001). Intensely pleasurable responses to music correlate with activity in brain regions implicated in reward and emotion. Proceedings of the National Academy of Sciences, 98(20), 11818-11823.

[3] Colwell, R., Hewitt, M., \& Fonder, M. (2017). The teaching of instrumental music. Routledge.

[4] Costa, A., \& Lowery, L. F. (2016). Techniques for teaching thinking. Routledge.

[5] Feierabend, J. M. (2001). Conversational solfege. Chicago: GIA.

[6] Haynes, B. (2002). A history of performing pitch: the story of 'A'. Scarecrow Press.

[7] Hoch, J. E., Bommer, W. H., Dulebohn, J. H., \& Wu, D. (2018). Do ethical, authentic, and servant leadership explain variance above and beyond transformational leadership? A meta-analysis. Journal of Management, 44(2), 501-529.

[8] Hofstede, G. (1983). The cultural relativity of organizational practices and theories.Journal of international business studies, 14(2), 75-89.

[9] Huron, D. B. (2006). Sweet anticipation: Music and the psychology of expectation. MIT press.

[10] Juslin, P. N. and P. Laukka (2003). Communication of emotions in vocal expression and music performance: Different channels, same code? Psychological Bulletin, 129, 770-814. 
[11] Kohut, D. L. (1973).Instrumental music pedagogy: Teaching techniques for school band and orchestra directors. Prentice Hall.

[12] Mandler, G. (1984). Mind and Body: Psychology of Emotion and Stress. New York: Norton.

[13] Manoff, T. (1982). Music: A Living Language. Instructor's Manual for Music, a Living Language.

[14] McClung, A. C. (2008). Sight-singing scores of high school choristers with extensive training in movable solfège syllables and Curwen hand signs. Journal of Research in Music Education, 56(3), 255-266.

[15] McEnnis, D. \& Cunningham, S. J. (2007). Sociology and music recommendation systems. Austria: Austrian Computer Society (OCG).

[16] Meyer, L. B. (1956). Emotion and Meaning in Music. Chicago: University of Chicago Press.

[17] Mitchell, H. F. (2018). Music students' perceptions of experiential learning at the moot audition. Music Education Research, 20(3), 277-288.

[18] Papageorgi, I., Hallam, S., \& Welch, G. F. (2007). A conceptual framework for understanding musical performance anxiety. Research studies in music education, 28(1), 83-107.

[19] Reifinger Jr, J. L. (2012). The acquisition of sight-singing skills in second-grade general music: effects of using solfege and of relating tonal patterns to songs. Journal of Research in Music Education, 60(1), 2642.

[20] Somekh, B. (1995). The contribution of action research to development in social endeavours: A position paper on action research methodology. British Educational Research Journal, 21(3), 339-355.

[21] Thompson, W. F. \& Quinto, L. (2011). Music and emotion: Psychological considerations. The aesthetic mind: Philosophy and psychology, 357-375.

[22] Thornton, P. H., \& Ocasio, W. (2008). Institutional logics. The Sage handbook of organizational institutionalism, 840, 99-128.

[23] Tuffour, Y. A. (2012). 1st Congregation Ceremony of Kaaf University College.

[24] Wallace, C. J., Liberman, R. P., MacKain, S. J., Blackwell, G., \&Eckman, T. A. (1992). Effectiveness and replicability of modules for teaching social and instrumental skills to the severely mentally ill. American Journal of Psychiatry, 149(5), 654-658.

[25] Whitener, J. L. (2007). The effect of practicing music classroom procedures on the behavior of middle school beginning band students. University of Southern California.

[26] Zhukov, K. (2012). Teaching strategies and gender in higher education instrumental studios. International Journal of Music Education, 30(1), 32-45.

\section{AUTHOR'S BIOGRAPHY}

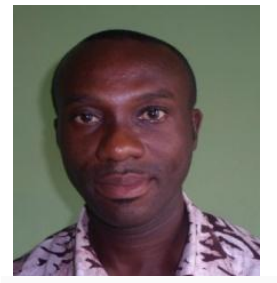

Mr. George Asabre Maclean is a lecturer in the Department of Music Education, University of Education, Winneba, Ghana. $\mathrm{He}$ is a scholar in Theory and composition and has much interest researching into issues pertaining to Composition, Choral music Performance and Wind instruments Pedagogies.

Citation: George Asabre Maclean. "Training Amateur Bandsmen to Perform at Functions: COLTEK Band in Perspective" International Journal of Humanities Social Sciences and Education (IJHSSE), vol 5, no. 7, 2018, pp. 157-167. doi: http://dx.doi.org/10. 20 431/2349-0381.0507018.

Copyright: (C) 2018 Authors. This is an open-access article distributed under the terms of the Creative Commons Attribution License, which permits unrestricted use, distribution, and reproduction in any medium, provided the original author and source are credited. 